\title{
A strategic framework for digital preservation in the context of e-government in Botswana public service
}

\author{
Keneilwe Margret Porogo \\ Ministry of Mineral Resources, Green \\ Technology and Energy Security, Botswana \\ Chibidukeneilwe1983@gmail.com
}

\author{
Trywell Kalusopa \\ University of Namibia \\ tkalusopa@unam.na
}

Received: 24 May 2021

Revised: 07 July 2021

Accepted: 23 August 2021

\begin{abstract}
The purpose of the study was to assess the digital preservation capability maturity readiness in the context of e-government in Botswana Public Service with a view to developing a strategic framework that ensures digital continuity. The study adopted a pragmatic paradigm and case study which were deployed in each of the six selected ministries as a unit of analysis. The target population was 102 respondents from six key purposively sampled ministries. Seventy-nine questionnaires were distributed, of which 55 were completed and returned. Interviews were conducted with 21 staff being senior managers, managers for human resources and administration, heads of divisions for records management units, archives unit, ICT managers and senior records managers. Formal participatory observations of documents were conducted. The study's findings showed that the Botswana public service has no unified national information systems to manage public sector records, which led to some ministries adopting their own electronic records management systems. Currently, few ministries have implemented the electronic records management system and most digital records are not preserved due to lack of preservation guidelines and strategies. In that regard, the study developed a strategic framework to safeguard digital continuity and make sure that e-government is sustained for the benefit of an open government and increased participatory citizenry.
\end{abstract}

Keywords: Botswana public service, digital maturity capability, digital continuity, digital records, digital preservation, e-government

\section{Introduction}

The efficient and effective management of e-records and advanced content is a cornerstone of every e-government operation in any country in today's computerised world. E-government is an essential tool acting as an enabler in the effective facilitation and coordination of information, and effective public service delivery across the government (Bwalya 2018a). This suggests there ought to be public area re-designing whereby the special and nonexclusive cycles can oblige the administration of advanced information brought by new technologies. As a result, most experts believe that as governments and businesses around the world adopt e-government methods, the rapid production and development of electronic 
records necessitates the use of electronic records management systems (Nengomasha 2009; Kalusopa \& Ngulube 2011; Tsabedze \& Kalusopa 2018). Implementing electronic records management systems is imperative given that the utilisation of e-government applications results in a significant amount of advanced electronic content whose quality and reliability need to be maintained (Tsabedze \& Kalusopa 2018).

Bwalya (2018b:19) agrees that e-government enables the re-engineering of conventional government administration systems rife with red tape into a transformed, more efficient public service delivery capacity. Digital records preservation is a vital area in records management as it ensures that digital records of proceedings with continuing value stays open and usable (ICA/IRMT 2016,110). The main purpose of digital preservation is safeguarding continuous access to digital records whenever needed, notwithstanding changes in technology. Pederson (2016) indicates that some developing countries neglected to adequately carry out e-government, leading to the high aptitude given the heterogeneity of innovation conditions in government organisations. In addition, Bwalya (2018a:v) expresses that with the fast progress in achieving e-government initiatives in Africa and throughout the world, there is a need to look at the key challenges inferable from the mistake of an enormous number of e-government projects. In recent years, Botswana's public service has implemented e-government systems as a programmes used to transform the public sector with the aim of enhancing service delivery (Jauhari, Abd Majid, Basri \& Djalil 2020).

Adu, Dube and Adjei (2016) posits that the relationship between digital preservation and egovernment is always symbiotic because effective and efficient recordkeeping in accordance with good practice gives meaning to the right to information for the citizens. As a drive towards e-government, the use of ICTs led to the creation of huge amounts of digital data both within the public and private sector. This amount of digital information can be daunting, given that digital records are more complicated and delicate than paper-based systems and, therefore, threaten the future sustainability of government information (Adu 2013:7). All government services may be provided online, depending on the maturity of e-government where it is implemented.

In recent years, the government of Botswana has deployed e-government systems as a programme employed to transform the public service aiming to improve service delivery. According to Nkwe (2012), the Botswana government strategy in 2011 aim was to move all services online, thus improving service delivery and accelerating the adoption of ICT in the society. Samboma (2019:3) states that the Botswana government implemented several egovernment projects systems and registered improvements in all indicators on technological readiness, and the country's path on ICT adoption in its governance process has been strengthened (Botswana Statistics 2019:4).

According to the National Development Plan 11, developing e-services broadband connectivity and implementing e-government project were prioritised (Government of Botswana 2017:70). Kalusopa, Mosweu and Bayane (2017:20) indicate that government ICTs infiltrated many, if not all, of Botswana's public sector agencies, even if they do not always interact with archives and records management systems. The problem of digital preservation remains a concern. Introducing technology, especially social media, is vital for a proper understanding of records preservation in future (Mosweu \& Ngoepe 2018). In Botswana, as in other countries, the growing development of electronic records in the public sector raised 
concerns among archivists, librarians and other custodians of such materials about the challenges of digital preservation (Kalusopa \& Zulu 2009). Botswana's public institutions are run on a manual electronic hybrid system, with room for change and greater emphasis on digital records management (Kalusopa et al. 2017:7).

According to the open data readiness report, Botswana already digitised many important datasets for this effort, and the re-invigorated e-government strategy provides the opportunity to ensure data from key systems can be easily extracted for publication of open data as and when the Botswana government decides to do so (Government of Botswana 2015). Current studies, such as those of Katuu (2016), raised similar issues regarding the poor state of digital preservation, without pointing to a clear framework for capability and maturity readiness in the public sector. This study aimed to develop a strategic framework ensuring permanent digital continuity for digital preservation capability maturity readiness in the context of egovernment in the Botswana public service.

\section{Statement of the problem}

Literature points out that Botswana is actively pursuing e-government but still face challenges with ensuring long-term digital records preservation to permanently secure and protect digital records for authenticity and potential access (Kalusopa \& Zulu 2009; Kalusopa et al. 2017). This is because the automation and re-engineering of systems and online resources and the preservation of digital records became more difficult. The World Bank Group (2014) uncovered that the Botswana National Archives Act of 2007 makes no specific arrangement for preserving and archiving digital records, as the policy and strategy are structured around paper records. Earlier studies by Kalusopa and Ngulube (2011), Kalusopa and Zulu (2009), Keakopa (2007), Kootshabe (2011), Moatlhodi (2015), Motupu and Kalusopa (2016), Moloi and Mutula (2007), and Wamukoya and Mutula (2005) discuss digital records preservation but not propose any framework for assessing digital preservation maturity readiness in the public service. One gap in these studies are that they did not show how digital preservation would ensure the continuous use of digital records over time with the view of retaining their accuracy, trustworthiness, authenticity, reliability and accessibility for current and future use. This study therefore assesses the e-government drive and digital preservation capability maturity and goes further to develop a framework that ensures permanent digital preservation continuity.

\section{Aim of the study}

The aim of the study was to develop a strategic framework ensuring permanent digital preservation continuity for digital records capability maturity readiness in the context of egovernment in the public service in Botswana.

\section{Research objectives}

The research objectives were:

- To assess the digital preservation infrastructure in terms of the policy, strategy, collaboration and technical expertise in the government ministries within the context of e-government. 
- To examine the trustworthiness of existing digital records in the Botswana government repositories in terms of accuracy, authenticity and reliability for effective e-government delivery.

- To assess digital preservation strategies delivered as part of e-government.

- To determine and compare at which stage each ministry is in terms of digital preservation capability maturity readiness.

- To propose an appropriate framework for the assessment of the digital maturity capability readiness in the Botswana public sector that can enhance e-government.

\section{Literature review}

The World Bank DGRA (2020:6) states most governments embarked on their digital change journey to improve administrative and operational efficiency by introducing the 'egovernment' model which mainly focused on putting e-services online by using ICT. Bwalya (2018:105) states there is still lack of sustainability in implementing e-government as many countries in Africa are facing challenges in adopting digital technologies. Li and Banach (2011) opine that in the digital era, preserving digital records has become more complex because digital information is fragile and faces many threats such as technological obsolescence and the deterioration of digital storage media.

\subsection{Digital preservation infrastructure in different countries}

According to the National Research Council (2001), developing infrastructure for digital archiving is driven by the need to support multiple communities. It was found that the South Africa National Archives developed guidelines for the administration of electronic records, but the absence of infrastructure makes difficult for organisations to realise the policy (Ngoepe \& Van Der Walt 2009). The administration and preservation of records in a digital environment are problematic because of absence of storage and preservation measures in many countries (Marutha \& Ngulube 2012:47-52). However, organisations do not oversee these records because of absence of framework, skills to safeguard and make them available in future (Ngoepe \& Keakopa 2011).

\subsection{Regulatory framework of managing records and digital preservation}

Several regulatory frameworks are used in Botswana to manage records. In Africa, there are concerns about digital preservation frameworks, legal and regulatory issues related to access of digital records over a long term (Gbaje 2011; Katuu \& Ngoepe 2015; Mutula 2014). Ngoepe and Keakopa (2011) and Kalusopa and Zulu (2009) express that Botswana's archival legislation is feeble to the extent that guidance cannot be provided on records and digital heritage materials preservation in Botswana.

\subsection{Trustworthiness of existing digital records in terms of accuracy, authenticity and reliability for effective e-government delivery}

Duranti (2014:14) expresses that accuracy or exactness is rightness and its content depends on the capability of its creator and the controls of its creation. Duranti and Rogers (2012) opine that trust in records depends on four types of knowledge about the records creator or custodian: reputation, past performance, competence and assurance of confidence in future 
performance. Mosweu (2019:56) demonstrates that authenticity is secured by establishing strategies that guarantee that a record is not controlled, altered or misrepresented after creation and that it remains reliable as it was initially created.

\subsection{Digital preservation strategies delivered as part of e-government}

Vermaaten, Lavoie and Caplan (2012) suggest that building an effective digital preservation strategy adds up to representing and alleviating different dangers to the accessibility and usability of digital records over time. Formal training opportunities for digital preservation are still rare (Note 2018).

\subsection{The level of ministries in terms of digital preservation capability}

As determined by Dollar and Ashley (2014), the Digital Preservation Capability Maturity model was created to empower organisations to assess the advancement measures and see key practices to improve constraints on those cycles. The model organises the digital preservation requirements of the ISO standards into 15 components with metrics to assess maturity. This study used this model to discover the preservation issues from the time digital records are created or captured, gaps identified, capability levels and preservation performance metrics found, priorities for achieving enhanced capabilities to preservation established and access to long-term digital records for the Botswana public service ensured.

In Botswana, the e-government vision is to become the integrated government by providing collective access to services in a convenient, efficient, transparent and reliable way (Madala \& Phirinyane 2015). The progress of e-government and digital preservation in Botswana is confronted with existing and new challenges, which have been pointed out by research. Despite the efforts made in the drive of e-government and digital preservation, this became a significant problem for the Botswana public service. Little is known about how the Botswana public service deals with the difficulty of ensuring that digital records continue to be available for the current and future generations. This study fills the gap in literature on digital preservation capability maturity readiness in the context of e-government in the public service in Botswana and Africa.

\section{Methodology}

The study used mixed methods data collection tools to gather data for the study. This implies that the researcher gathered qualitative and quantitative data simultaneously and consecutively to have one type of information assume a supportive role to the other. Data was collected from senior managers, heads of divisions for records and archives, ICT managers, records managers and records officers from the six ministries sampled through interviews. The questionnaires were administered to records managers and chief records officers. Formal participatory observation was conducted. These were the Ministries of Transport and Communication, Land Management Water and Sanitation Services, Finance and Economic Development, Employment, Labour Productivity and Skills Development, Investment Trade and Industry, and Youth Sport and Culture. 


\section{Findings and discussions}

Seventy-nine questionnaires were distributed, of which 55 were completed and returned, yielding a $70 \%$ response rate. Twenty-four $(30 \%)$ were not completed and returned. The response rate for questionnaires was $70 \%$. The targeted number for interviews was 23 participants but only 21 were interviewed, giving a $91 \%$ response rate. Only $2(9 \%)$ officers did not participate. One participant had a tight schedule and the other was on an official trip. The participants were coded to preserve anonymity. The respondents were coded as follows:

Table1: Coding f Participants

\begin{tabular}{|l|l|l|}
\hline \multicolumn{1}{|c|}{ No. } & \multicolumn{1}{|c|}{ Participants } & \multicolumn{1}{c|}{ Coding } \\
\hline 1. & Senior Manager - Corporate Services & SM-CS 1, 2 and 3 \\
\hline 2. & $\begin{array}{l}\text { Manager - Human Resources Management and } \\
\text { Administration }\end{array}$ & $\begin{array}{l}\text { M-HRM } \\
\text { Administration 1, 2 and 3 }\end{array}$ \\
\hline 3. & $\begin{array}{l}\text { Information Communication Technology } \\
\text { Managers }\end{array}$ & ICT-M 1, 2, 3, 4 and 5 \\
\hline 4. & Head of Division - Records Management & HOD-RM 1, 2, 3 and 4 \\
\hline 5. & Head of division - Archives & HOD-A \\
\hline 6. & Senior Records Manager & SRM 1 and 2 \\
\hline
\end{tabular}

\subsection{Types of systems for managing digital records}

During the interview participants were asked the type of systems that their ministries used to manage digital records. They made remarks as follows:

M-HRM and Administration 2, 3, ICT-M 1, 3, 4, 5, HOD RM 3, 4 and SRM 1, 2 reported "The current systems which are used are the Land Administration Procedures Capacity and Systems (LAPCAS), oracle system and the government accounting budgeting system commonly known as GABS, Document Workflow Management System, expatriates employment system and National Archives and Records Management System." 


\subsection{File formats in the ministries}

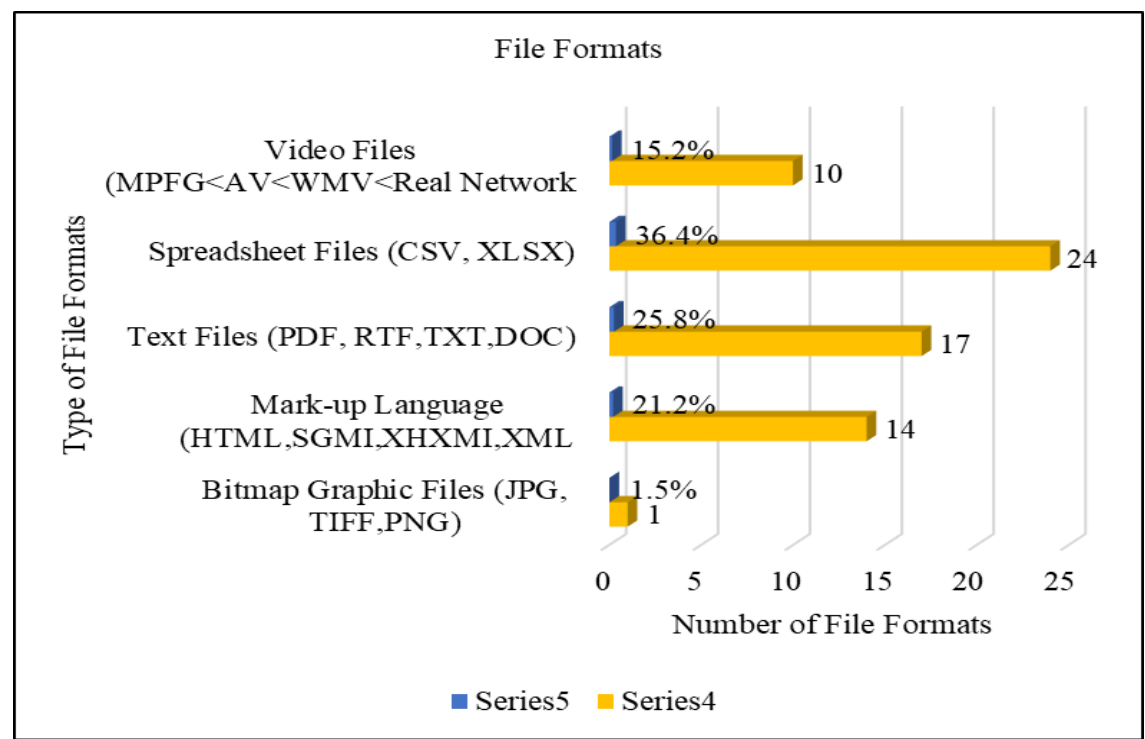

Figure 1: File formats

Respondents were asked to identify the file formats held in their ministries. The findings in Figure 1 shows that $1(1.5 \%)$ respondent reported they used bitmap graphic files in their ministry, while $14(21.2 \%)$ stated they used mark-up language, 17 (26\%) said text files, 24 (36.4\%) indicated spreadsheet files, and 10 (15.2\%) specified video files. Formal participatory observations showed emails that were used as a form of communication formats were created in a text document, while their attachments were in PDF/A. The results confirmed that the Botswana public service creates vast amounts of information solely in digital form and most of these are of permanent value, yet they are at risk because of fragile media, technological obsolescence, or other hazards.

\subsection{Policy guidelines and standards for managing digital records}

The respondents were asked to find out whether ministries have written preservation policies guiding the management of digital records. Four (6.1\%) respondents stated there was a preservation policy for the management of digital records, while $62(93.9 \%)$ reported there was none. 


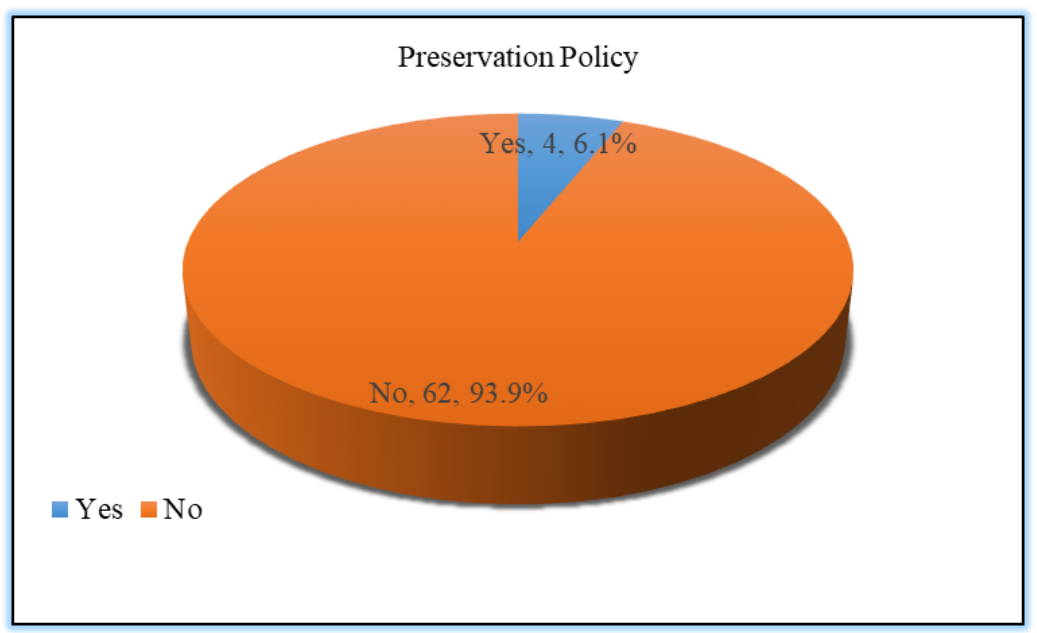

Figure 2: Preservation Policy

The findings in Figure 2 indicate the Botswana government ministries lack written preservation policies. Formal participatory observations showed the preservation policy that was at draft stage at the Botswana National Archives and Records Services has long been under development and, yet, the department made no comments or suggestions. These findings imply the lack of clear policy related to protection of digital data might encourage the assumption that the protection of digital records is not a priority in the Botswana Public Service. The documentary review revealed the National Archives and Records Service Act of 2007 was inadequate and ineffective as it makes no provision for data archiving or digital preservation. The findings support Gbaje and Mohammed (2013), Ngoepe and Keakopa (2011), Moloi and Mutula (2007), Kalusopa and Zulu (2009) and Nengomasha (2009) who found out that legislation, policy and guidelines for electronic records management were inadequate.

\subsection{Digital preservation strategies}

The respondents were asked to state the digital preservation strategies used by ministries in mitigating the obsolescence of storage devices and file formats. The results showed that few attempts were made such as migration, data backup, refreshing and ministerial disaster planning. Figure 3 below shows data preservation used by ministries.

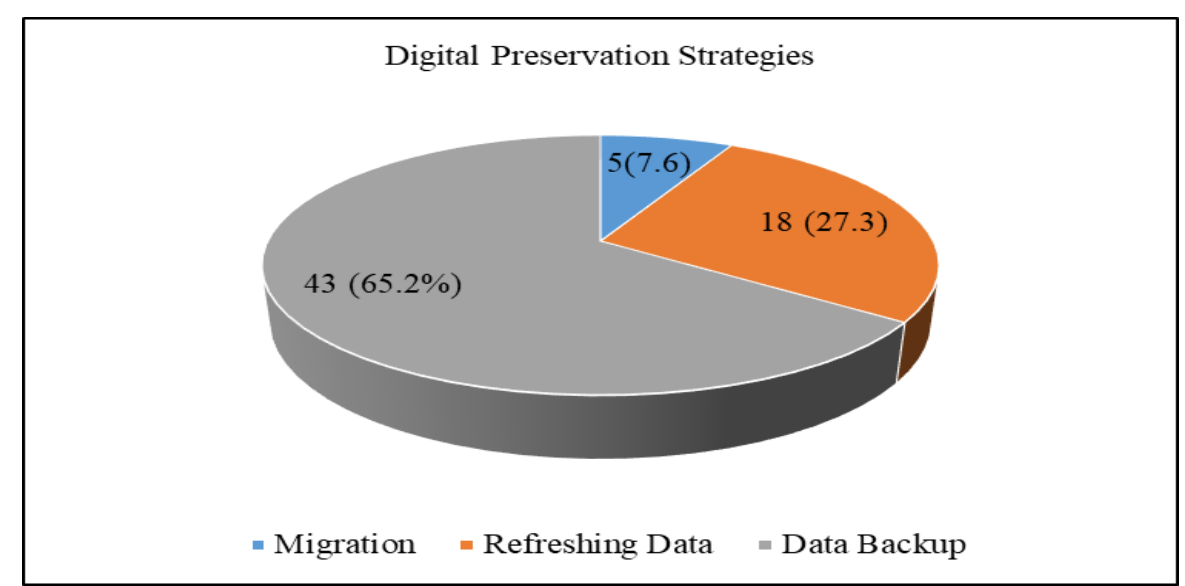

Figure 3: Migration Preservation Strategy 
Figure 3 shows $5(7.6 \%)$ ministries use migration, indicating that migration practices vary among ministries and some do not appear to be integrated into digital preservation programmes or processes. Furthermore, it seems this migration strategy was used in conjunction with larger system upgrade.

\subsection{Data backup preservation strategy}

Figure 3 indicates that $43(65.2 \%)$ respondents said they used data backup as preservation strategy. Formal participatory observation revealed that at the Department of Information Technology, data was transferred to offline storages after 10 years. This strategy does not guarantee long-term digital preservation due to poor infrastructure of some servers and missing information kept in the servers. During interviews, participants reported as follows: ICT-M 2 and 3 stated they save backups of official documents on an internal server that is managed by the information technology department. According to ICT-M 2, 3 and 5, the infrastructure of their servers was outdated, and they had to back up information on it. By 2017, all the information stored on the server had been affected by a virus, and nothing could be restored since then.

The respondents SRM 2, M-HRM, Administration 1, 2, and ICT-M 1, 2, 3 and 4 all said "The backup strategy is carried out by information technology officers on hard drives as well as servers, and there are officers responsible for server monitoring on a daily basis, resulting in our confidence that the material is secure."

These findings concur with Corrado and Moulaison (2015) that back-up strategy is suitable for short- to medium-term preservation of digital records. This denotes that if the Botswana public service continues to back up data, they can easily identify and replace corrupted or missing digital files on the systems.

\subsection{Collaboration and engagement}

Dollar and Ashley (2013) state that organisations with a mandate to preserve digital records are well served by maintaining and promoting collaboration among its stakeholders. Thirtyfive $(53 \%)$ respondents indicated they collaborate with Botswana National Archives and Records Services, 16 (24\%) said Botswana Bureau of Standards, 12 (18\%) said Botswana National Library Services and $3(5 \%)$ indicated Botswana Broadcasting Services. It is important for ministries to collaborate on digital preservation to be seen as one government. 


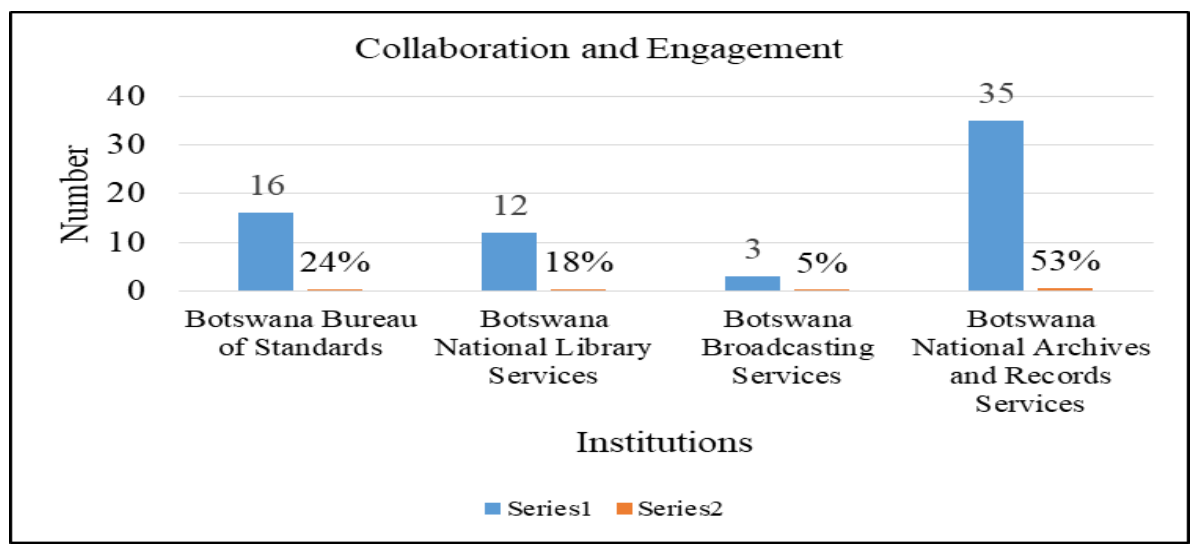

Figure 4: Collaboration and Engagement

\subsection{Technical expertise}

According to Adu (2013), to empower digital preservation specialist with technological (systems), metadata (categorical) and collection skills are needed. The findings in Figure 5 show that $18(27 \%)$ respondents had technical expertise on the systems they were using, while $48(73 \%)$ did not have technical skills they could use in planning activities for longterm digital preservation. The findings support Katuu and Ngoepe (2017) and Mosweu and Ngoepe (2018) that records management professionals lacked skills in computing, metadata and digital preservation to manage digital records.

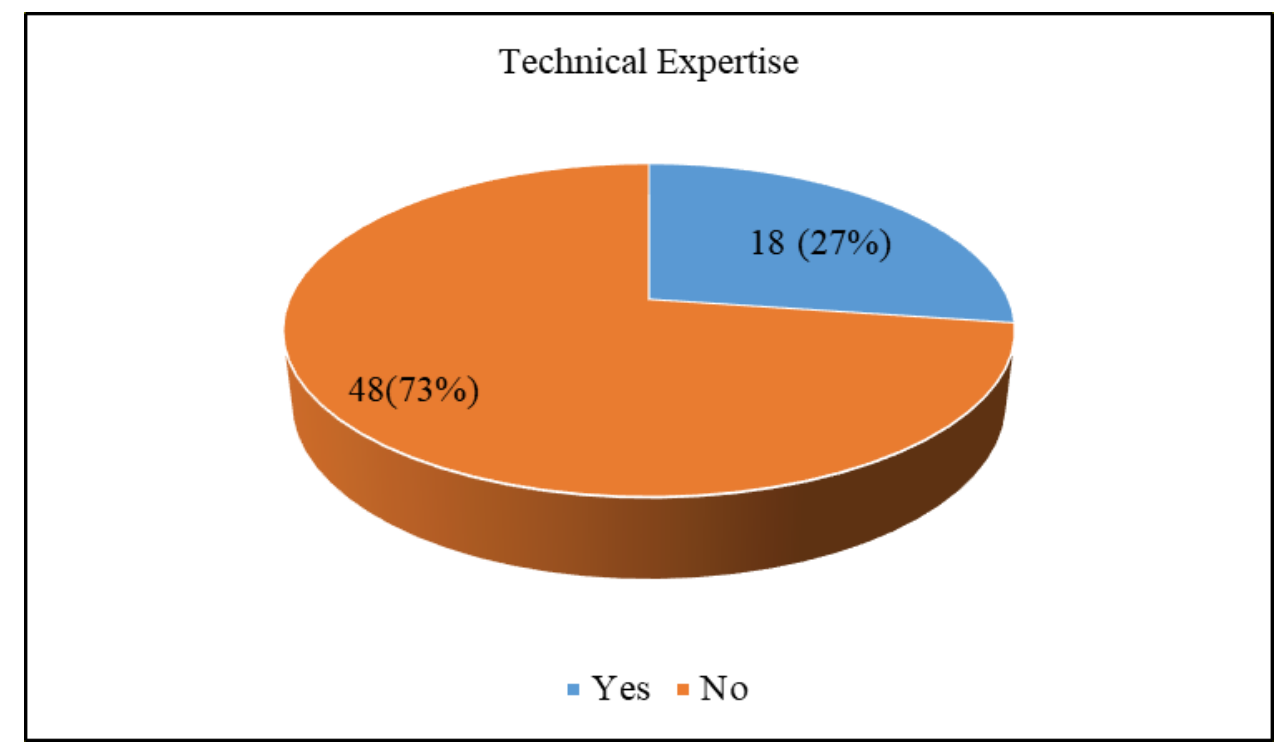

Figure :5 Technical Expertise

\subsection{Authenticity and reliability of trusted digital repository for effective e-government delivery}

Xie and Matusiak (2016) stipulate that digital repositories are information systems that ingest, store, maintain, retain and make digital content available. When asked about the reliability and trust provided by the digital repositories, participants said:

ICT-M 1, 3, HOD RM, HOD Archives, SRM 1 and 2 reported the digital records in DIT custody are unsecure and have no integrity. 
ICT-M 2 and 4 stated the server's infrastructure was very weak and they were unable to preserve digital records past their expiration date, resulting in irretrievability and loss.

HOD RM 1, ICT-M 5 and SM 3 informed that most customers were dissatisfied with their service. For example, land allocation in the country is problematic because the country lacks sufficient information on plots assigned to individuals.

\subsection{Appraisal of digital records}

Eastwood (2004) opines that the essence of appraisal involves making a judgement or estimation of the worthiness of continued preservation. Fifty-eight $(88 \%)$ respondents indicated there were no procedures in place for the transfer of digital records during the appraisal process. Eight (12\%) stated they transferred digital records from their ministries to Botswana National Archives for preservation. Formal participatory observation showed that at the Botswana National Archives Records Centre, videos were kept in a cold room of some ministries. A transfer manual revealed no guidelines for digital records transfer.

\subsection{Metadata and authenticity}

The findings obtained through observation revealed that metadata was used in their digital records creation. The respondents were asked which metadata they used and its authenticity in digital records creation. The results showed $36(55 \%)$ respondents indicated descriptive, 15 $(23 \%)$ structural, $10(15 \%)$ administrative and $5(8 \%)$ were not sure. Formal participatory observation revealed that administrative metadata was common, as well as the file types or modules, the date and description of file creations and classified access rights. During interviews, respondents were asked whether they used classification schemes and retention and disposal schedules to ensure authenticity. Their responses are shown below:

ICT-M 1, 2, 3, 4 and 5 stated "The classification scheme and retention schedule are solely used by RMU staff on paper records; other business systems do not require records management tools, and records within the system cannot be deleted."

M-HRM \& Admin 2, SRM 2 and HOD RM 5 reported "The classification scheme requires approval from the Botswana National Archives and Records Services, which takes time. We could not wait any longer and decided to deploy the system while waiting for approval."

\subsection{A reliable operation of information systems for digital records}

Digital records must be managed in a record-keeping system as they produce authentic and reliable records (Oliver and Harvey 2016). During interview officers were asked to show how they ensure authenticity in information systems. Participants remarked as follows:

ICT-M 5 stated "Long-term preservation of the authenticity of records, in my opinion, is a risky proposition." 
ICT-M 2 and 4 informed they "could not guarantee network availability during system upgrades, the records that will be preserved at that time may not be kept, and there may be no backup archive showing that those exact records exist."

ICT-M 1 reported "The system in our ministry allows us to decommission records, which means a record may be trusted to be used for decision-making."

Formal participatory observations revealed the systems used authentic records as they used lightweight directory access protocol from the ministries. Using passwords and usernames allowed the verification of records' identity and integrity by the system administrators.

\subsection{Security and access for authentic (fixity) digital records}

Respondents were asked to describe how ministries safeguard digital records against unauthorised access, tampering and viruses. Figure 6 highlights that $25(37.9 \%)$ respondents used online password management or hygiene as a protection measure, while $41(62 \%)$ used desktop passwords to shield their digital records from being accessed.

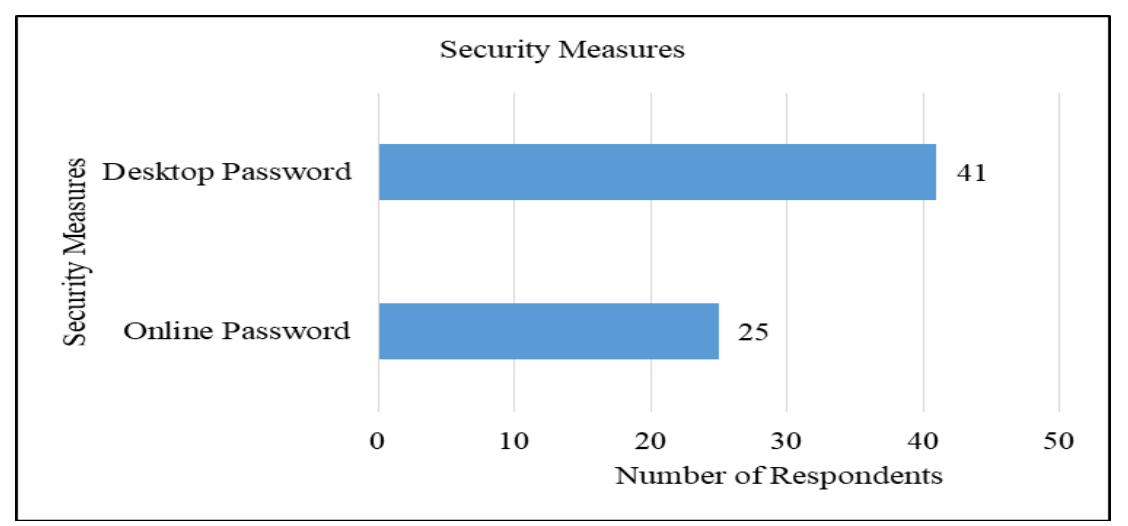

Figure 6: Security Measures

The interview findings indicated that firewalls were used as a security measure.

ICT-M 2 and 3 reported all the systems used to generate digital records had up to date properly maintained firewalls.

ICT-M 1, 3 and 5 informed that the system has been installed in the local area network (LAN); hence, a desktop, not web-based application, and all the users who had access rights are given desktop passwords.

Participatory observations showed there were different approaches to computer system security management or hygiene such as a firewall. A firewall had rules that filtered out unwanted intrusions and made it more difficult to access the system. Security classifications were assigned and records officers were issued individual passwords to prevent unauthorised access to the systems. In all the systems used, each password was associated with a specific username, as many officers were accessing the same system.

\subsection{Storage of digital records}

Appropriate and good records storage ensures that records are accessible, accurate, and authentic and they are stored for as long as they are required (Kalusopa \& Ngulube 2011). 
Respondents were asked to describe the type of digital records storage they use. Figure 7 indicates that $42(64 \%)$ of respondents used CD-ROM or DVD, while $17(26 \%)$ said they were kept as part of a digital preservation repository system and $17(11 \%)$ said they outsource to a service provider on a contract basis.

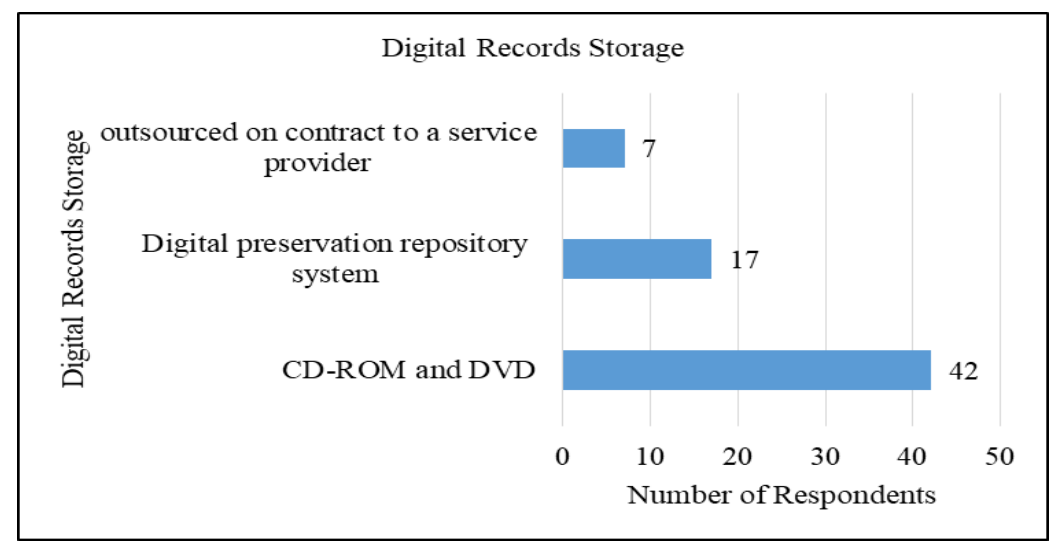

Figure 7: Digital Records Storage

\subsection{Cloud storage}

When asked whether they see cloud storage as part of their storage architecture, $11(17 \%)$ responded said they stored some information in cloud storage while $55(83 \%)$ did not (Figure 8. Formal participatory observation showed Botswana public service made few attempts to store digital information in the cloud.

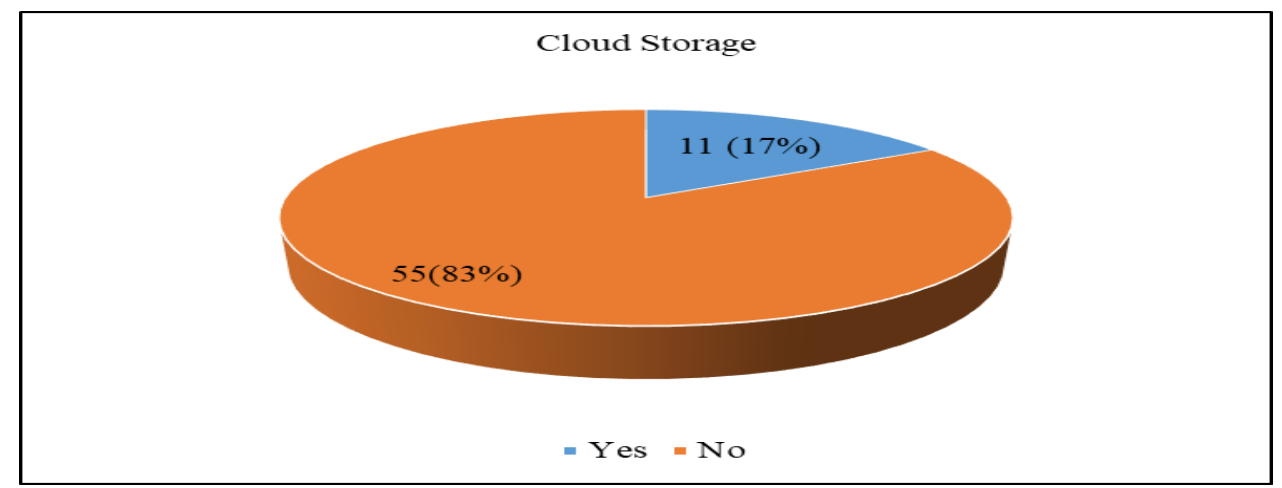

Figure 8: Cloud Storage

\subsection{Proposed framework}

The essence of the framework explains what Botswana public service should do to ensure the long-term preservation of digital records as follows:

\section{E-government strategy}

The proposed framework takes into consideration Botswana's e-government strategy and the issue of digital records preservation. The study established that Botswana public service were still at the beginning stage of e-government. The study proposes the review of e-government strategy, incorporating digital preservation of records. 


\section{Digital preservation strategy}

The study indicates lack of digital preservation strategy, but the strategy has to be developed, which should incorporate the issue of digital continuity so that digital records survive technical obsolescence and losses to make them accessible to those needing them. The strategy should take into consideration the policy, standards and infrastructure to improve the services of e-government.

\section{Digital preservation policies}

The findings showed lack of policies for managing digital records. The study proposed proactive development of policies and procedures for preserving digital records. The policy should incorporate issues related to access, use and reuse of digital records. Access, security and privacy controls are crucial for effective and sustainable digital preservation programmes and strategies.

\section{Technical skills}

The framework proposes a need for technical skills, which should include computer-related activities, appraisal and selection of digital records. Records management professionals in the Botswana public service should be able to take a holistic view of a repository's activities, and develop a smooth workflow that eliminates redundant steps and increases efficiency and effectiveness.

\section{Collaboration and engagement}

The framework proposes a need for records professionals to work together. This entails building collaborative networks across a wide range of disciplines. They should strive to build positive, supportive work relationships.

\section{Integrated electronic systems}

The study further established that interoperability between e-government and digital records systems in Botswana public service was problematic. The Ministry of Information Technology should share this responsibility to ensure seamless management of digital records preservation in the context of e-government strategy. The integration would include both hardware and software harmonisation of systems, and eliminate duplication of processes.

\section{Metadata and standards}

This study revealed lack of standards for management of digital records. The study proposes the adoption of standards and metadata that will enable management of digital records over time. Botswana public service uses systems that are not integrated so this study proposed that for different systems to work together in a technological environment, information professionals need shared specifications for interoperability. Preserving metadata supports the long-term digital preservation goals to maintain the availability, identity, persistence, renderability, understandability, and authenticity of digital objects over long periods.

\section{Database preservation}

The framework recommends a database preservation of digital records. The database will include all the contextual information explaining provenance, function, covering dates, technical information, ingestion process, database schema and the transformations performed. 


\section{Trusted digital repositories}

The framework underscored the need for trusted digital repositories for managing digital records over time. This will facilitate the management of digital records and guarantee longterm storage and access of archival materials by users.

\section{Ingestion of digital records}

Data will be prioritised and categorised which will make data flow smoothly in further layers in data ingestion process flow. The amount of digital records created in Botswana public service needs efficient methods and tools to help transfer records into trusted long-term repositories.

\section{Preservation strategies}

The framework proposes the adoption of a comprehensive strategy ensuring that those who substantially influence the existence, character, or accessibility of digital records contribute to the accomplishment of that function. Botswana public service needs to implement digital preservation strategies that anticipate ICT obsolescence and incompatibility.

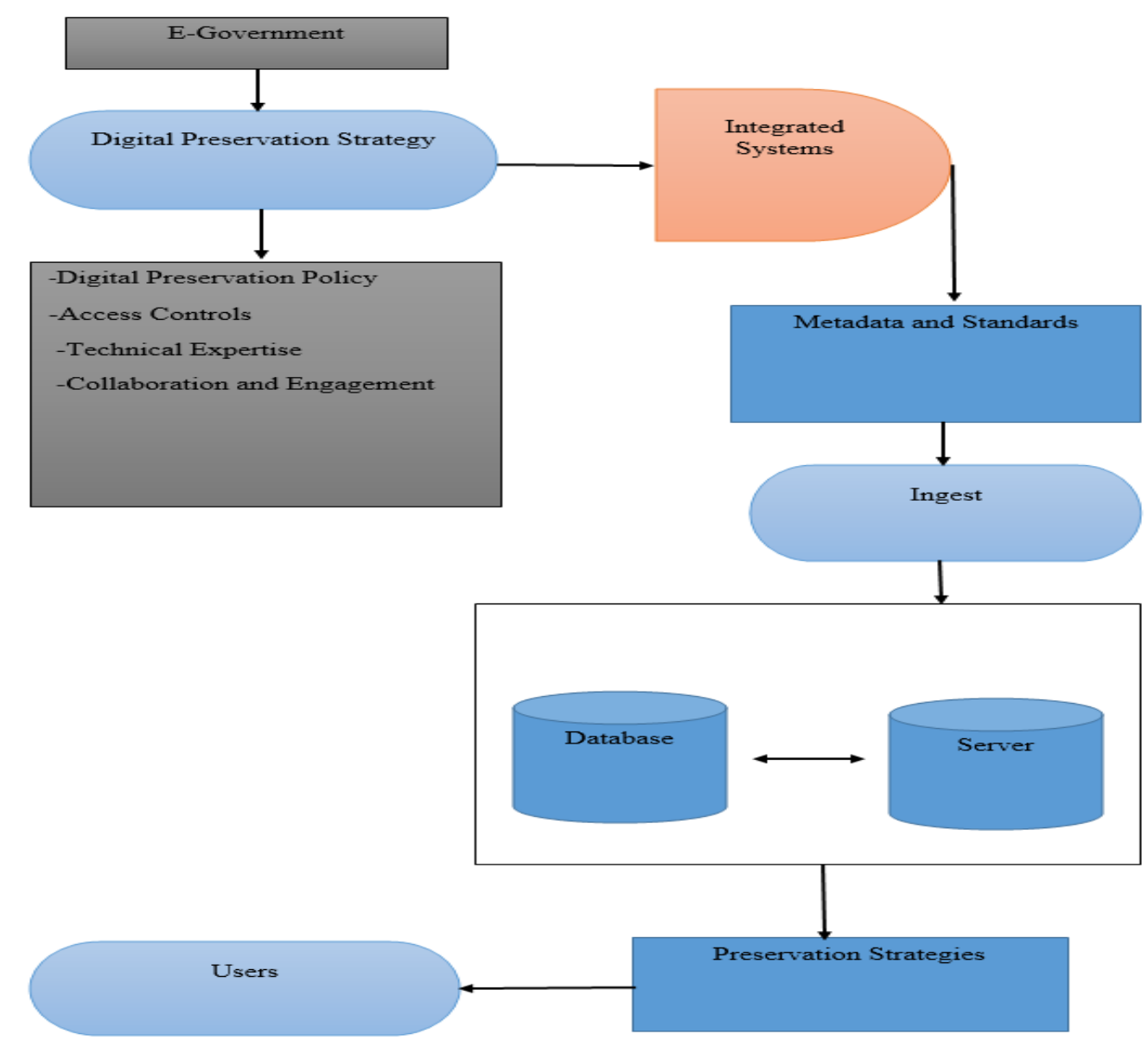

Figure 9: Proposed Framework 


\section{Explanation of the framework}

This proposed framework was built on the existing knowledge gap in the digital preservation in the context of e-government. This proposed framework borrowed ideas from the digital preservation capability maturity model. The components of the framework are depicted above.

\section{E-government}

There is a need for e-government and digital preservation to be incorporated by making repositories with large capacity to accommodate the Botswana public service information for future use. This will assist the e-government projects to survive sustainably.

\section{Digital preservation strategy}

There is a need to use digital preservation strategies to prevent digital records obsolescence so that they remain accessible for business transactions. This means the development and implementation of the control measures, procedures, re-engineering of processes that guard against the authenticity, reliability and accessibility of digital records.

\section{Integrated systems}

Botswana public service must take steps to ensure records management provides accurate, unaltered and useable information. This necessitates the integration of records management solutions into ICT systems.

\section{Metadata and standards}

Metadata is key to digital preservation but not for accessibility purposes, rather for preserving the history of a record to figure out what has been done to the file, changes it has gone through, being able to detect its originality (Hart \& De Vries 2017:2). This study suggests and stresses the development of a new global standard that will address each type of a metadata by taking all the existing and new elements so that they complement each other.

\section{Ingesting digital records}

Digital records need to be ingested into databases and servers, but this should be done after the identification of the provenance, making backup copies as a way of verifying metadata integrity, and scanning of viruses and other forms of malicious code. If this procedure is successfully completed, records should be transferred into digital repositories, servers and databases.

\section{Users}

Humans play a pivotal therefore they must be competent enough to bring effective solutions to preservation problems. According to Hart and De Vries (2017: 18), there is a need for professional ethics, skills, attitude and monitoring that are very important for digital preservation. The Botswana public service must implement a comprehensive training and skills programme aimed at developing digital preservation practical, useful skills at all levels of government.

\section{Conclusion}

The study findings revealed lack of repositories or data centres and absence of preservation policy to be used for managing digital records. The Botswana public service did not have any 
plan to preserve their digital records in the cloud due to lack of technical skills of records staff to advise on the benefits of preserving digital records so that they do not get lost but rather keep providing authentic, reliable, accessible and trustworthy evidence of the Botswana public service history.

\section{References}

Adu, K.K. 2013. Ghana's Right to Information Bill: an opportunity for the implementation of digital preservation infrastructure. Journal of Emerging Trends in Computing and Information Sciences 4:10.

Adu, K.K., Dube, L. \& Adjei, E. 2016. Digital preservation: the conduit through which open data, electronic government and the right to information are implemented. Library Hi Tech 34(4):733-747.

Bwalya, K.J. 2018a. Decolonisation of e-government research and practice: exploring contextual issues and opportunities in Africa. AOSIS.

Bwalya, K.J. 2018b. The e-government development discourse: analysing contemporary and future growth prospects in developing and emerging economies. AOSIS.

Corrado, E.M. \& Moulaison, H.L. 2015. Digital preservation and the cloud: Challenges and opportunities. In IFLA 2015 Pre-Conference Satellite Meeting Preservation \& Conservation Section.

Dollar, C.M. \& Ashley, L.J. 2013. Assessing digital preservation capability using a maturity model process improvement approach. Available at: https://www.nycarchivists.org/Resources/Documents/DollarAshley_2013_DPCMM\% 20White\%20Paper_NAGARA\%20Digital\%20Judicial\%20Records_8Feb2013-1.pdf (accessed 15 August 2020).

Duranti, L. 2014. Involuntary secondary permanence: do many copies replace the original? Available at: https:interparestrust.org/assests/public/dissemination/Duranti2014YaleLibraries.pdf (Accessed 23 May 2020).

Eastwood, T. 2004. Appraising digital records for long-term preservation. Data Science Journal. 3:202-208. Available at:

https://www.jstage.jst.go.jp/article/dsj/3/0/3_0_202/_article/-char/ja/ (accessed 09 February 2020).

Duranti, L. \& Rogers, C. 2012. Trust in digital records: An increasingly cloudy legal area. Computer Law \& Security Review 28(5):522-531.

DOI: https://doi.org/10.1016/j.clsr.2012.07.009.

Franks, P. \& Kunde, N. 2013. Why metadata matters. http://www.arma.org/bookstore/files (accessed 19 March 2019).

Gbaje, E.S. 2011. Digital preservation strategies: a case study of Nigerian national information centres. IFLA Journal 37(93):218-227.

Government of Botswana, 2017 Botswana National Development Plan. Gaborone: Government Printer.

Hart, T.R. \& De Vries, D. 2017 Metadata provenance and vulnerability. Information Technology and Libraries 36(4):24-33. DOI: https://doi.org/10.6017/ital.v36i4.10146

ICA/IRMT 2016. Understanding digital records preservation initiatives. Available at: https://www.ica.org/sites/default/files/Digital\%20Preservation\%20Initiatives\%Module _0.pdf (accessed 30 January 2018). 
Jauhari, A., Abd Majid, M. S., Basri, H., \& Djalil, M. A. 2020. Are EGovernment and Bureaucratic Reform Promoting Good Governance 186 towards a Better Performance of Public Organization? Calitatea 21(175): 25-30.

Kalusopa, T., Mosweu, T. \& Bayane, S. 2017. Implementation of enterprise-wide systems to manage trustworthy digital records in Botswana's public sector Paper Presented at ESARBICA Bienial General Conference In Lilongwe, Malawi, 7-11 August.

Kalusopa, T. \& P. Ngulube. 2011.E-records readiness: building a contextual framework for labour organization in Botswana. XXI Bi-Annual East and Southern Africa Regional Branch of the International Council on Archives (ESARBICA) Maputo, Mozambique.

Kalusopa, T. \& Zulu, S. 2009. Digital heritage material preservation in Botswana: problems and prospects. Collection Building.

Katuu, S. 2016. Overview of the InterPARES Trust project in Africa: trusting records in an increasingly networked environment. New Review of Information Networking 21(2):117-128.

Katuu, S. \& Ngoepe, M. 2015. Managing digital records in a South African public sector institution. INFuture2015 e-institutions-openness, accessibility and preservation. Crotia: University of Zagreb 135-141.

Katuu, S. \& Ngoepe, M. 2017. Education and training of archives and records management professionals in Africa. SCEaR Newsletter 1:22-27.

Keakopa, S.M. 2007. Policies and procedures for the management of electronic records in Botswana, Namibia and South Africa. ESARBICA Journal: Journal of the Eastern and Southern Africa Regional Branch of the International Council on Archives 26.

Kootshabe, T.G. 2011. Preservation of records in selected government ministries and departments in Botswana. MARM dissertation, University of Botswana, Gaborone.

Li, Y, \& Banach, M. 2011. Institutional repositories and digital preservation: Assessing current practices at research libraries. D-lib Magazine 17: 5-6.

Madala, N.C. \& Molefe, B.P. 2016. Strengthening local government service delivery systems through the open government initiative: the case of Botswana. Botswana Institute for Development Policy Analysis (BIDPA).

Marutha, N.S. \& Ngulube, P. 2012. Electronic records management in the public health sector of the Limpopo province in South Africa. Journal of the South African Society of Archivists 45:39-67.

Mnjama, N. 2014. Archival legislation and archival services in Africa. In Digital access and e-government: perspectives from developing and emerging countries, IGI Global, pp. 27-47.

Moatlhodi, T., 2015. An assessment of e-records readiness at the Ministry of Labour and Home Affairs in Botswana. Unpublished Masters thesis, University of Botswana, Gaborone.

Moloi, J. \& Mutula, S. 2007. E-records management in an e-government setting in Botswana. Information Development 23(4):290-306.

Mosweu, O. \& Ngoepe, M. 2018. Legal framework for auditing public sector accounting records in the digital environment in Botswana. In Proceedings of the 9th ProLISSA Conference. Newcastle upon Tyne: Cambridge Scholars.

Mosweu, O. 2019. Knowledge and skills requirements for a records manager in Botswana in the networked environment. Journal of the South African Society of Archivists 52:110132.

Motupu, K. 2016. Assimilation of e-government systems at the Ministry of Trade and Industry in Botswana. 
National Research Council. 2001. LC21: A digital strategy for the Library of Congress. National Academies Press.

Nengomasha, C.T. 2009. A study of electronic records management in the Namibian public service in the context of e-government. PhD dissertation, University of Namibia.

Ngoepe, M. \& Keakopa, S.M. 2011 An assessment of the state of national archival and records systems in the ESARBICA Region: a South Africa-Botswana Comparison. Records Management Journal 21(2):145-160. DOI: https://doi.org/10.1108/0956561111152071

Ngoepe, M. \& Van Der Walt, T. 2009. An exploration of records management trends in the South African public sector. Mousaion 27:1.

Nkwe, N. 2012. E-government: challenges and opportunities in Botswana. International Journal of Humanities and Social Science 2(17):39-48.

Note, M. 2018. Three fundamental digital preservation strategies. https://lucidea.com (accessed 23 November 2020).

Pederson, K., 2016. e Government in Local Government: Challenges and Capabilities. Electronic. Journal of E-government 14(1): 99-116.

Tsabedze, V. \& Kalusopa, T. 2018. Towards a framework for e-records readiness in support of e-government in eSwatini. ESARBICA Journal: Journal of the Eastern and Southern Africa Regional Branch of the International Council on Archives 37:39-68.

Vermaaten, S., Lavoie, B. \& Caplan, P. 2012. Identifying threats to successful digital preservation: the SPOT model for risk assessment. D-lib Magazine 18(9/10):1-21.

Wamukoya, J. \& Mutula, S. 2005. E-records management and governance in East and Southern Africa. Malaysian Journal of Library \& Information Science 10(2):67-83.

World Bank. 2020. Digital government readiness assessment toolkit: guidelines for task teams.

Xie, I. \& Matusiak, K.K., 2016, Discover digital libraries: Theory and practice, Elsevier, Amsterdam 